\title{
Seven plus initiative: the way forward to stem Dengue
}

\section{Santosh Kumar, Sheen Job}

Associate Professor, Department of Community \& Family Medicine, All India Institute of Medical Sciences Rishikesh; MPH PG, School of Public Health, All India Institute of Medical Sciences Rishikesh

\begin{tabular}{|c|c|c|c|c|c|c|c|c|}
\hline Abstract & Introduction & Methodology & Results & Conclusion & References & Citation & \multicolumn{2}{|c|}{ Tables / Figures } \\
\hline \multicolumn{9}{|c|}{ ling Autho } \\
\hline \multicolumn{8}{|c|}{$\begin{array}{l}\text { Dr Santosh Kumar, Associate Professor, Department of Community \& Family Medicine, AllMS } \\
\text { Rishikesh, Uttarakhand. } \\
\text { E Mail ID: drsantoshbhu@gmail.com }\end{array}$} & 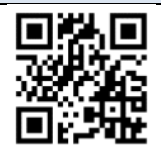 \\
\hline
\end{tabular}

\section{Citation}

Kumar S, Job S. Seven plus initiative: the way forward to stem Dengue. Indian J Comm Health. 2020;32(4):751753. https://doi.org/10.47203/IJCH.2020.v32i04.026

Source of Funding: Nil Conflict of Interest: None declared

\section{Article Cycle}

Received: 25/11/2020; Revision: 05/12/2020; Accepted: 13/12/2020; Published: 31/12/2020 This work is licensed under a Creative Commons Attribution 4.0 International License.

\section{Abstract}

The vector-borne disease has been a public health challenge in the country since long. The menace of dengue, every rainy season only draws attention towards the need for community participation to combat this problem. Dengue has come out to be a social problem which mostly depends upon the environment and habitation of humans. The overwhelming concern over the increasing burden and its dire consequences, a multidisciplinary team was constituted which comprised of local leaders, ASHA, ANM and NGOs, destined to encourage community participation for dengue prevention. A seven-plus initiative was started by this multidisciplinary team which aims to mitigate the larva life cycle of dengue from the breeding site in seven days. This initiative was completely based on active surveillance of breeding sites, tracking fever cases and active implementation of source reduction measures coupled with insecticide spray.

\section{Keywords}

Dengue, Community participation, Active surveillance, Prevention

\section{Introduction}

Post monsoon period in India brings about a plethora of problems both for the administration and the health services. The infectious disease such a dengue is difficult to curb even with the best of efforts, by the health services.(1) Though the first confirmed dengue case was reported in 1960, effective mosquito control is still a challenge as very little can be done by health agencies who are committed to the task such as public engineering. There is a dearth of knowledge, awareness and the good practices to be followed in the community. Since Independence, India has been fighting its own battle, to control infectious diseases, but significant change is yet to be seen, despite huge investments in health sector for the same.(2)
Mosquito breeding has been a scourge despite the control measures (3). The Accredited Social Health Activist (ASHA) is a health worker, belonging to the local community and is skilled to impart awareness and knowledge on preventive measures in the locality. This is akin to the erstwhile barefoot doctors in the Chinese villages who were responsible for a paradigm shift in health.(4)

The role of community members, which includes the Gram Pradhan, the ward members of the panchayat council, the volunteers, the religious leaders, the political activists or leaders, teachers of educational institutions, is crucial to bring about the change in attitude of people in the community. These role models are part of the local population and exert much influence on the community than the health 
workers. An innovative approach coupled with commitment to motivate and dispel the ignorance in the residents of the locality is the root mantra to convince people to adopt good practices to preventive mosquito borne disease (5).

\section{Material \& Methods}

The Seven plus initiative is a community based preventive health initiative against dengue. It comprises of a multidisciplinary team, doctors, public health nurses, community leaders, health services representatives and ASHA workers. The concept of seven plus programme was based on to tear out the larva life cycle from the breeding sources which developed in seven days. Community participation and behavior change of community and individuals with aim to live in dengue free environment was the essential key of this initiative (6). High risk areas on the basis of previous data of dengue cases were mapped, multidisciplinary team was trained and sensitized with the issue that dengue is more and less a social problem not absolutely the medical problem. Active surveillance of breeding sites, fever cases and active implementation with source reduction and insecticide spray. It was evaluated in previous studies also the susceptibility of dengue is higher among farmers, children and those who are unaware about breeding site (7). Active participation of stakeholders in discarding broken containers, water drainage system management was reported to be effective in dengue control (8). After continuous intensive awareness and active surveillance for a period of seven days it was followed by monitoring and advocacy of this initiative.

\section{Results}

Five indicators were considered for the monitoring and evaluating the outcome of the 7 initiative (Figure 1) following the intervention.

1. Fever cases

2. Larva in stagnant water

3. Stagnant water sites

4. Number of coolers

5. Number of coolers and stagnant water with active mosquito breeding (larva)

Following the intervention, comprising of house-tohouse health awareness campaign, identification of mosquito breeding sources within and outside the household, emptying the water coolers and stagnant water sources, larvicidal measures (figure 2) and checking fever cases, as part of active surveillance
Individual awareness and role in the Community, Community Perspective on Prevention, Advocacy and Political Commitment have shown positive outcomes.

\section{Conclusion}

The concerted efforts of prominent leaders within the given community help make preventive measures in Dengue more sustainable and productive. We may therefore conclude that health services, including personnel combined with community engagement, can go a long way to eliminate the dengue outbreaks and mitigate the social menace forever. The community's wellbeing can be better handled by effective cooperation between the different stakeholders. This eradication model, through the initiative of Dengue $7+$, initiative, may be imbibed in various preventive health programs.

\section{References}

1. World Health Organization. National guidelines for clinical management of dengue fever. India: World Health Organization. 2015

2. Williamson DR, Albert $M$, Heels-Ansdell $D$, Arnold DM, Lauzier F, Zarychanski R, Crowther M, Warkentin TE, Dodek P, Cade J, Lesur O, Lim W, Fowler R, Lamontagne F, Langevin S, Freitag A, Muscedere J, Friedrich JO, Geerts W, Burry L, Alhashemi J, Cook D; PROTECT collaborators, the Canadian Critical Care Trials Group, and the Australian and New Zealand Intensive Care Society Clinical Trials Group. Thrombocytopenia in critically ill patients receiving thromboprophylaxis: frequency, risk factors, and outcomes. Chest. 2013;144(4):1207-1215. doi: 10.1378/chest.13-0121. PMID: 23788287.[PubMed].

3. Buckley MF, James JW, Brown DE, Whyte GS, Dean MG, Chesterman CN, Donald JA. A novel approach to the assessment of variations in the human platelet count. Thromb Haemost. 2000;83(3):480-4. PMID: 10744157. [PubMed].

4. Ajlan BA, Alafif MM, Alawi MM, Akbar NA, Aldigs EK, Madani TA. Assessment of the new World Health Organization's dengue classification for predicting severity of illness and level of healthcare required. PLoS neglected tropical diseases. 2019;13(8):e0007144.

5. World Health Organization. National guidelines for clinical management of dengue fever. India: World Health Organization. 2015

6. Parks W, Lloyd L. Planning Social Mobilization and Communication for Dengue Fever Prevention and Control. A Step-by-Step Guide. Geneva, Switzerland: WHO, 2004. Available from: http://whqlibdoc.who.int/publications/2004/9241591072. pdf (Last Accesed on 2020 Dec 20).

7. Dengue risk factors and community participation in Binh Thuan Province, Vietnam, a household survey.Phuong HL, De Vries PJ, Boonshuyar C, Binh TQ, Nam NV, Kager PA Southeast Asian J Trop Med Public Health. 2008; 39(1):7989. [PubMed] [Ref list] 
8. Claro LB, Kawa H, Cavalini LT, Rosa MLG. Community participation in dengue control in Brazil. Dengue Bulletin. 2006;30:214-222. [Google Scholar] [Ref list]
9 Dutta AK, Biswas A, Baruah K, Dhariwal AC. National guidelines for diagnosis and management of dengue fever/dengue haemorrhagic fever and dengue shock syndrome. J Indian Med Assoc. 2011;109:30-5.

\section{Figures}

\section{FIGURE 1 DENGUE INDICATORS, PRE ANALYSIS, BEFORE INTERVENTION}

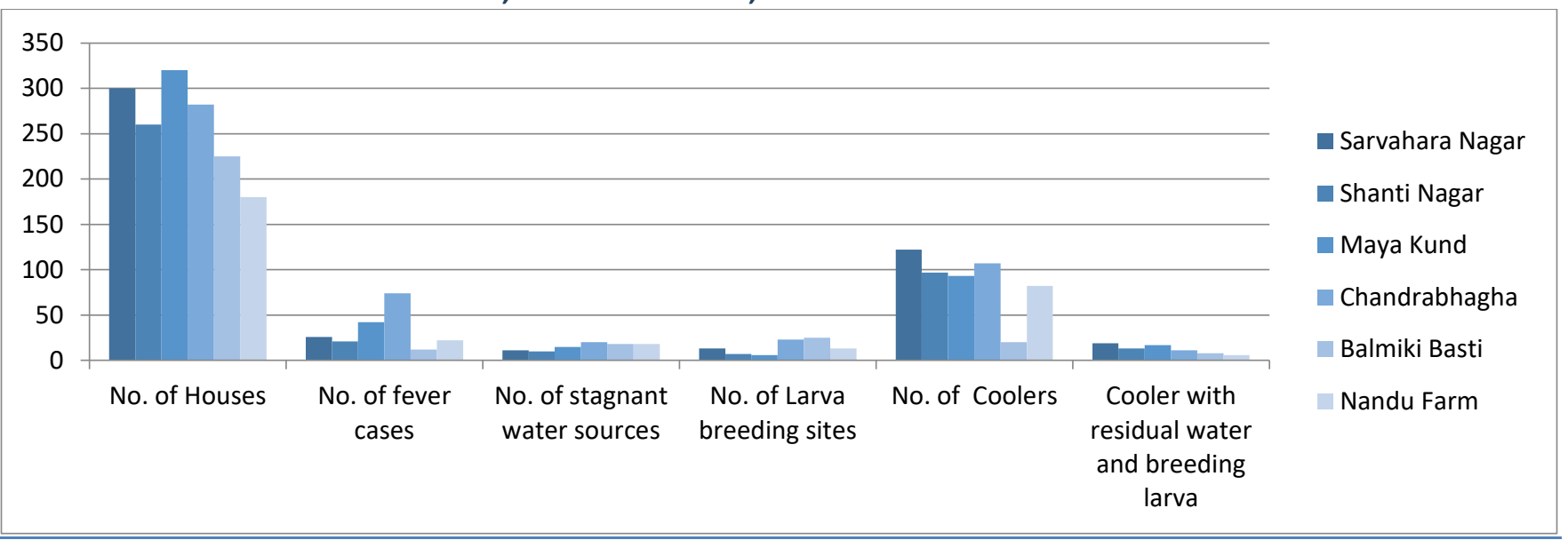

\section{FIGURE 2 DENGUE INDICATORS, POST ANALYSIS, AFTER INTERVENTION}

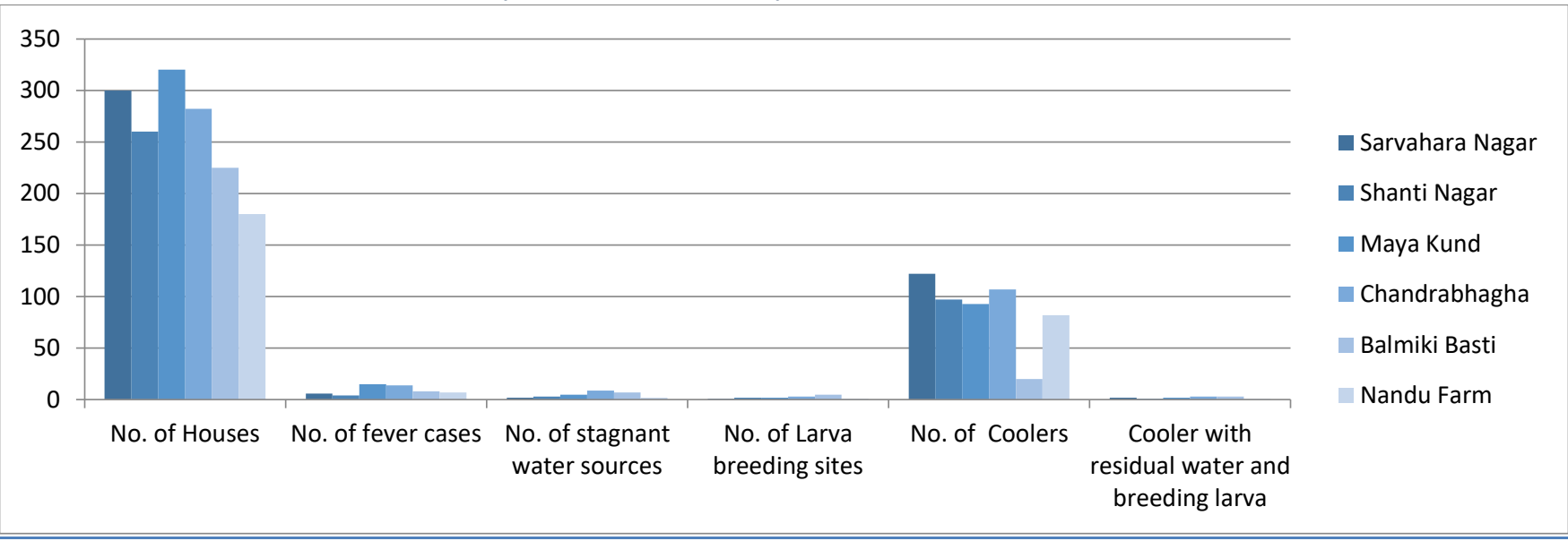

\section{FIGURE 3 SEVEN PLUS INITIATIVES FOR DENGUE PREVENTION}

\begin{tabular}{|c|c|}
\hline 2 Days & $\begin{array}{l}\text { - Social mappping of suspected area in community } \\
\text { - Selection of Potential breeding site in community (Hot Spot) } \\
\text { - Preparation of multidisciplinary team (Medical +Municipality +Local administration +ICMR team +Local agency +political team) } \\
\text { - Local awareness among selected spot through IEC (Poster, announcement and Community Mobilization). } \\
\text { - Training of municipality employee, ward members, local leader with ASHA, ANM for dengue prevention and control. }\end{array}$ \\
\hline ays & $\begin{array}{l}\text { - Active disease surveillance based on strong health information system } \\
\text { - Surveillance of active breeding site and locate for necessary action } \\
\text { - Active surveillance for household fever cases for suspected dengue (As per guidelines) (information collected by ANM, ASHA and } \\
\text { municipality members). } \\
\text { - Suspected dengue case reporting to AllMS Rishikesh for investigation } \\
\text { - Simultaneous implementation of larvicidal measures and insecticides spray }\end{array}$ \\
\hline $\begin{array}{l}2 \text { Days } \\
\text { (Sustained) }\end{array}$ & $\begin{array}{l}\text { - Communication for impact full behaviour change for sustainable disease control } \\
\text { - Advocacy for acceptation in the community. } \\
\text { - Sustained the practices for prevention } \\
\text { - Personal selling/interpersonal communication/counselling: } \\
\text { - Point-of-service promotion } \\
\text { - Continious monitoring and supervison } \\
\text { - local administrative support to amintain sustainability }\end{array}$ \\
\hline
\end{tabular}

